J. Clin. Chem. Clin. Biochem.

Vol. 28, 1990, pp. 193-197

(C) 1990 Walter de Gruyter \& Co. Berlin · New York

\title{
A New Chemiluminescence Immunoassay for Triiodothyronine and Thyroxine: Evaluation Using Quality Control Sera Assayed in an Interlaboratory Survey
}

\author{
By G. C. Zucchelli, A. Pilo, S. Masini, Maria Rosa Chiesa and Concetta Prontera \\ Istituto di Fisiologia Clinica, Consiglio Nazionale delle Ricerche (C.N.R.), Pisa, Italy
}

(Received July 11/November 6, 1989)

\begin{abstract}
Summary: A recently developed chemiluminescence immunoassay system (LIA-mat) for triiodothyronine and thyroxine, set up by Byk-Sangtec Diagnostica (Dietzenbach, Germany), has been evaluated and compared with radioimmunoassays and with a chemiluminescence enhanced enzyme immunoassay (Amerlite), using control materials circulated in a national interlaboratory quality control, as well as patient sera. The LIAmat assays are competitive methods which use coated monoclonal antibodies and triiodothyronine- or thyroxine-ABEI (aminobutylethylisoluminol) conjugate as tracers. The working range of LIA-mat T3 (computed from the within-assay precision profile) extended from 1.4 to $12.3 \mathrm{nmol} / \mathrm{l}$; the between-assay precision was $8.1-19.3 \mathrm{CV} \%$. Regression analysis of the LIA-mat T3 results (y) against the consensus means (x) of the participants in the national interlaboratory survey yielded: $y=-0.14+1.05 \mathrm{x}, \mathrm{r}=0.95$. The working range of LIA-mat T4 extended from 33 to $515 \mathrm{nmol} / \mathrm{l}$; the between-assay precision was $5.4-9.2 \mathrm{CV} \%$. An excellent agreement was found between LIA-mat T4 results (y) and the consensus means (x) of the laboratories participating in the national interlaboratory survey $(y=3.79+1.02 \mathrm{x}, \mathrm{r}=0.98)$.
\end{abstract}

\section{Introduction}

Thyroxine $\left(\mathrm{T}_{4}\right)$ and triiodothyronine $\left(\mathrm{T}_{3}\right)$, two of the most routinely assayed hormones in the clinical laboratories, are generally measured by radioimmunoassay (RIA). Although these techniques are fast and easy to perform and exhibit good precision and accuracy, they pose some problems mainly related with the short shelf-life of the tracers and the high costs of disposal of radioactive waste. Consequently some non-isotopic immunoassays, using enzymes, fluorescent dyes or chemiluminescent compounds as labels, have been developed and are now commercially available $(1-3)$.

Recently a new competitive luminescent assay for triiodothyronine and thyroxine (LIA-mat) was developped by Byk-Sangtec Diagnostica, Dietzenbach FRG; this technique employs $T_{3}$ and $T_{4}$ conjugated with an isoluminol derivative as tracers, and a bound/ free separation method with coated tube technology. We report here a methodological evaluation of LIAmat based on the results from control materials circulated in a national interlaboratory survey and from patient sera. A comparison with RIA methods and with a chemiluminescence enhanced enzyme immunoassay (Amerlite) was also carried out.

\section{Materials and Methods}

Analytical procedures

The LIA-mat $T_{4}$ and LIA-mat $T_{3}$ are non-isotopic, competitive immunoassays based on chemiluminescence. $T_{4}$ or $T_{3} \operatorname{tracer}\left(T_{4}\right.$ or $T_{3}$ conjugated with aminobutylethylisoluminol - ABEI and purified by HPLC) competes with the hormone present in the samples for the binding sites of a specific monoclonal antibody (anti- $\mathrm{T}_{4}$ or anti- $\mathrm{T}_{3}$ ) coated on tubes. 
Patient sample $\left(50 \mu l\right.$ for $T_{4}$ and $100 \mu l$ for $\left.T_{3}\right)$ is incubated at room temperature in the coated tube with $200 \mu \mathrm{l}$ of tracer, on a shaker; the incubation time is $2 \mathrm{~h}$ for thyroxine and $3 \mathrm{~h}$ for triiodothyronine. After incubation, the supernatant is aspirated and the test tubes are washed three times with $2 \mathrm{ml}$ of distilled water. Test tubes containing the bound fraction of the label are measured by an automatic luminometer (AutoCliniLumat, Berthold L B912). The chemiluminescence reaction is initiated by the automated injection into the luminometer of alkaline hydrogen peroxide in the presence of microperoxidase. Photon output is accumulated during $5 \mathrm{~s}$ and expressed as RLU (relative light units). The conversion of the measured RLUs (analytical response) into thyroxine or triiodothyronine concentration is performed automatically through spline interpolation of the dose-response curve (with 7 calibrators for thyroxine and 6 calibrators for triiodothyronine) which are carried out in each run.

To evaluate the performance of the LIA-mat technique, 8 thyroxine assays and 10 triiodothyronine assays were carried out; both calibrators and samples were assayed in duplicate.

\section{Control material and samples}

Lyphochek immunoassay control sera (BioRad Laboratories, Italy) and the control material included in the LIA-mat kits were used in each assay to estimate the between-assay precision.

The accuracy of the results of the LIA-mat technique were compared with those of other immunoassays by assaying control materials previously circulated in the national interlaboratory quality control (QC) for immunoassays, which was organized by us and supported by National Research Council, CNR (4). These QC materials consisted of 51 pools which were distributed on $1-5$ occasions during the period 1986-1988 to about 200 laboratories. The method/kits used by the participants in the interlaboratory survey were mostly radioimmunoassays ( $>90 \%$ ). The consensus means of the results reported by all participants in the QC survey were assumed as reference values and compared with the determinations produced by LIAmat.

Moreover, samples from normal, hypo- and hyper-thyroid patients, previously determined in our laboratory using RIA Spac and Amerlite, were assayed by LIA-mat to compare the performances of these three methods. RIA Spac (technique developed by Byk-Sangtec Diagnostica, and very similar to LIAmat except for the tracer) and Amerlite (chemiluminescence enhanced enzyme immunoassay (5), produced by Amersham International, UK) were carried out following the directions of the manufacturers.

\section{Estimation of the precision profile}

The mean precision profiles (6) were computed from data of all the assays, using a previously described computer program (7). In particular the response variability was modelled by a RER (response error relationship) of the type: $\operatorname{Var}(R)=K_{1} R$ $+\mathrm{K}_{2} \mathrm{R}^{2}$, and the two parameters $\left(\mathrm{K}_{1}, \mathrm{~K}_{2}\right)$ were determined using all duplicates (standards and samples) of the assays (8). The sensitivity (lowest detection limit) is read on the precision profile as the lowest concentration distinguishable from zero (confidence limit $\pm 2 \mathrm{SD}$ ) or concentration corresponding to $50 \% \mathrm{CV}$. The working range was also derived from the precision profile, as the concentration range measurable with a withinassay precision better than $10 \% \mathrm{CV}$.

\section{Results and Comments}

\section{Precision}

The reproducibility of the analytical response (RLU) of thyroxine and triiodothyronine assays was evaluated from all duplicates (both of the calibrators and of the unknown samples); figure 1 shows the mean $\mathrm{CV}$ of all the duplicates subdivided into 5 response intervals (both for $T_{3}$ and for $T_{4}$ assay). We found that the $\mathrm{CV}$ of the response for LIA-mat $\mathrm{T}_{4}$ was $3.8 \%$ on average; the precision of the response of LIA-mat $\mathrm{T}_{3}$ was worse (5.2 CV\% on average). In both assays the $\mathrm{CV}$ of the response was found to be approximately constant in the measurement range.
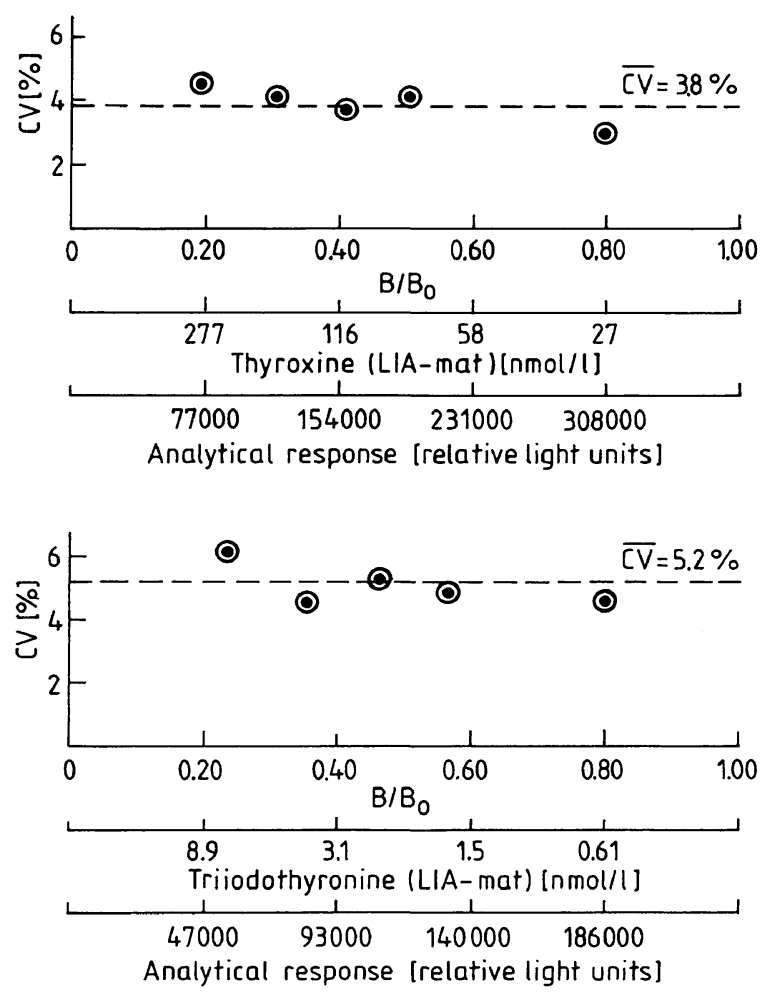

Fig. 1. Variability of the analytical response (relative light units) of LIA-mat T4 and LIA-mat T3. Response (abscissa) is reported both as RLU and as $B / B_{0}$; corresponding triiodothyronine or thyroxine concentrations are also indicated.

The mean dose-response curves are depicted in figure 2 ; when expressed as $\mathrm{B} / \mathrm{B}_{0}$ they are very similar to the calibration curves of the methods RIA Spac $\mathrm{T}_{3}$ and $\mathrm{T}_{4}$.

Starting from the variability of the response and the slope of the dose-response curve, the precision profiles of the $T_{4}$ and $T_{3}$ LIA-mat were computed; figure 2 reports the mean precision profiles of LIA-mat compared with those for the RIA Spac technique. We found that, as far as thyroxine assay is concerned, the within-assay precision of the luminescent and isotopic 

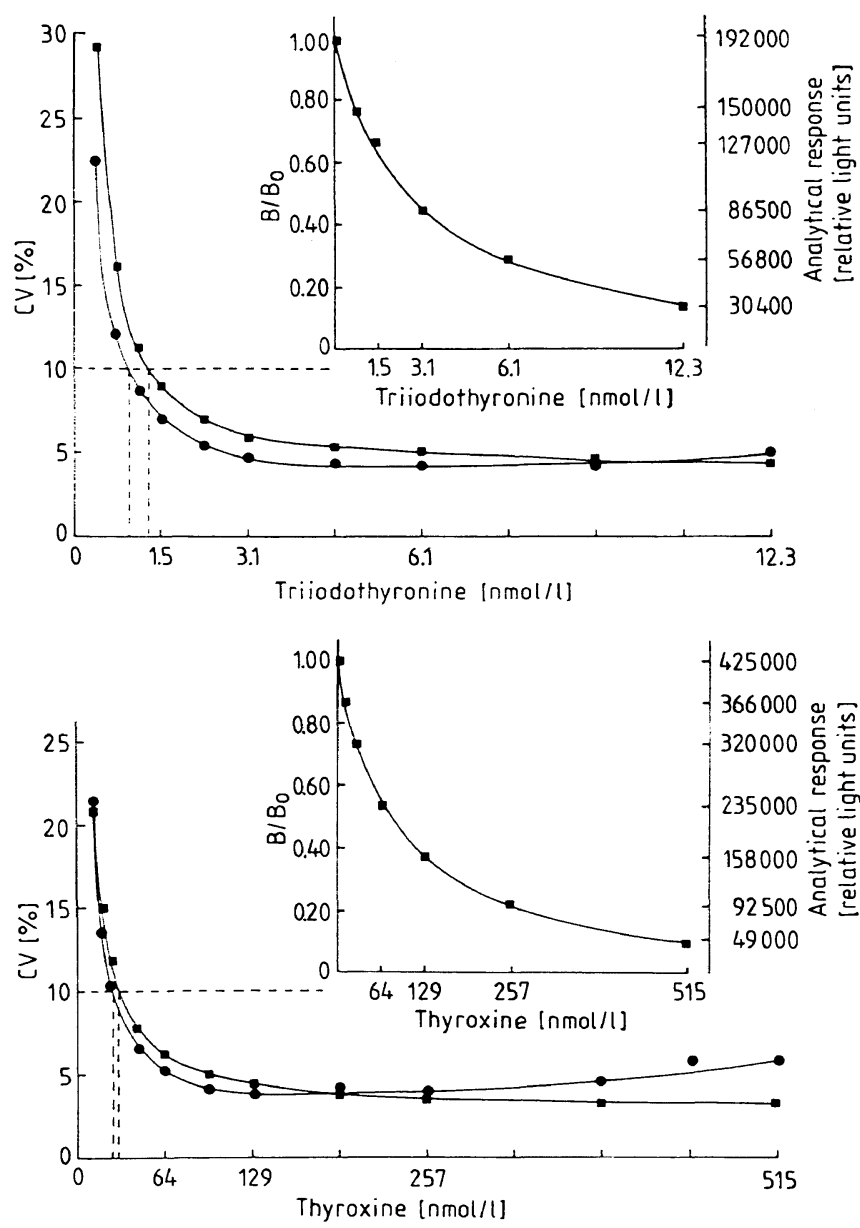

Fig. 2. Mean precision profiles for LIA-mat T3 and LIA-mat T4 (closed squares); precision profiles of RIA Spac T3 and T4 (closed circles) are reported for comparison. Typical dose-response curves of LIA-mat T3 and LIAmat T4 (closed squares) are also depicted in the inset figures.

The sensitivity is read on the precision profile as the lowest concentration distinguishable from zero (confidence limit $2 \mathrm{SD}$ ) or concentration corresponding to $50 \% \mathrm{CV}$; the lower limit of the working range is read as the lower concentration measurable with a withinassay precision better than $10 \% \mathrm{CV}$ (dashed lines). The following values were found:

\begin{tabular}{llllll}
\hline & \multicolumn{2}{l}{$\begin{array}{l}\text { Triiodothyronine } \\
\text { nmol/1 }\end{array}$} & \multicolumn{2}{l}{$\begin{array}{l}\text { Thyroxine } \\
\text { nmol/l }\end{array}$} \\
\cline { 2 - 3 } & $\begin{array}{l}\text { LIA- } \\
\text { mat }\end{array}$ & $\begin{array}{l}\text { RIA } \\
\text { Spac }\end{array}$ & & $\begin{array}{l}\text { LIA- } \\
\text { mat }\end{array}$ & $\begin{array}{c}\text { RIA } \\
\text { Spac }\end{array}$ \\
\hline $\begin{array}{l}\text { Sensitivity } \\
\begin{array}{l}\text { Lower limit of the } \\
\text { working range }\end{array}\end{array}$ & $\begin{array}{l}0.23 \\
1.40\end{array}$ & 0.18 & & 5.3 & 6.6 \\
\hline
\end{tabular}

systems are very similar (LIA-mat $\mathrm{T}_{4}$ : sensitivity 5.3 $\mathrm{nmol} / 1$, lower limit of the working range $33 \mathrm{nmol} / \mathrm{l}$; RIA-Spac $\mathrm{T}_{4}$ : sensitivity $6.6 \mathrm{nmol} / 1$, lower limit of the working range $27 \mathrm{nmol} / \mathrm{l})$. On the other hand, the within-assay precision of LIA-mat $\mathrm{T}_{3}$ was somewhat worse than that of RIA Spac (LIA-mat $\mathrm{T}_{3}$ : sensitivity $0.23 \mathrm{nmol} / 1$, lower limit of the working range 1.4 nmol/1; RIA Spac $\mathrm{T}_{3}$ : sensitivity $0.18 \mathrm{nmol} / \mathrm{l}$, lower limit of the working range $0.97 \mathrm{nmol} / \mathrm{l}$ ); in particular the relatively high $\mathrm{CV}$ in the range $1.1-1.3 \mathrm{nmol} / \mathrm{l}$ makes it difficult to differentiate between hypothyroid and low normal triiodothyronine values.

Data on the between-assay precision of the LIA-mat $\mathrm{T}_{3}$ and $\mathrm{T}_{4}$ are reported in table 1 ; it can be seen that the precision of the thyroxine assay is better $(\mathrm{CV}$ range: $5.4-9.2 \%$, except for the low concentration QC sample) than that of the triiodothyronine assay (CV range: $8.1-19.3 \%$, except for the low concentration QC sample). This finding partially reflects the poorer within-assay precision of the triiodothyronine assay.

\section{Accuracy}

Results of regression analysis of LIA-mat triiodothyronine and thyroxine determinations against the consensus means of the interlaboratory survey in about 100 QC samples derived from 51 pools (most of which were sent on more than one occasion as hidden replicates) are reported in figure 3.
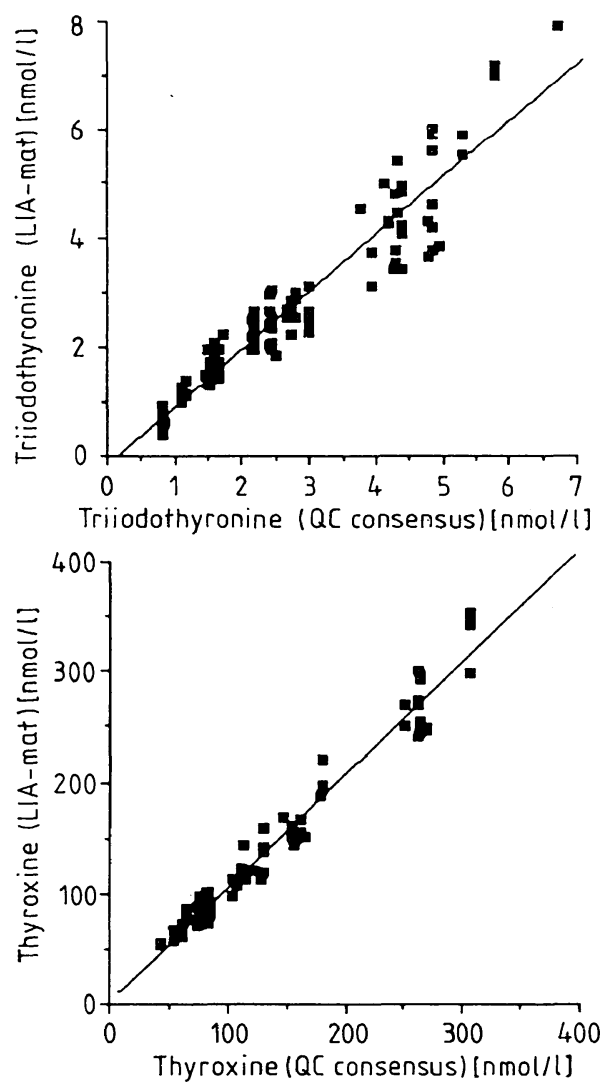

Fig. 3. Regression analysis of LIA-mat T3 results (upper panel: $\mathrm{y}=-0.14+1.05 \mathrm{x}, \mathrm{r}=0.95, \mathrm{n}=101)$ and LIA-mat T4 results (lower panel: $\mathrm{y}=3.79+1.02 \mathrm{x}, \mathrm{r}=0.98$, $\mathrm{n}=89$ ) against the respective consensus means from the interlaboratory survey, assumed as reference values. 
Tab. 1. Between-assay precision of T3 and T4 LIA-mat

\begin{tabular}{|c|c|c|c|c|c|c|c|}
\hline \multicolumn{4}{|c|}{ Triiodothyronine, nmol/1 } & \multicolumn{4}{|c|}{ Thyroxine, nmol/1 } \\
\hline & $\mathbf{n}$ & $\overline{\mathrm{x}} \pm \mathrm{SD}$ & $\mathrm{CV} \%$ & & $\mathrm{n}$ & $\overline{\mathrm{x}} \pm \mathrm{SD}$ & CV\% \\
\hline L1 & 10 & $0.48 \pm 0.12$ & 25.8 & L1 & 8 & $44.5 \pm 9.6$ & 21.5 \\
\hline POO6 & 4 & $1.40 \pm 0.21$ & 15.0 & PO16 & 6 & $53.7 \pm$ & 5.4 \\
\hline $\mathrm{CK}$ & 10 & $2.06 \pm 0.40$ & 19.3 & PO36 & 4 & $68.7 \pm$ & 9.2 \\
\hline $\mathrm{POO} 3$ & 5 & $2.14 \pm 0.27$ & 12.4 & L2 & 8 & $91.8 \pm$ & 9.1 \\
\hline L2 & 10 & $2.95 \pm 0.32$ & 10.8 & $\mathrm{CK}$ & 8 & $130 \pm 9.9$ & 7.6 \\
\hline PO19 & 3 & $4.50 \pm 0.40$ & 8.9 & L3 & 8 & \pm 16 & 7.4 \\
\hline L3 & 10 & $6.39 \pm 0.52$ & 8.1 & & & & \\
\hline
\end{tabular}

$\mathrm{L} \quad=$ Lyphochek control serum

$\mathrm{CK}=$ control material included in the kit

$\mathrm{P}=$ control material sent in the interlaboratory survey

It is evident that both triiodothyronine and thyroxine LIA-mat systems produce results in good agreement with the consensus means assumed as reference values. The lower value of the regression coefficient observed for the triiodothyronine assay is attributable to the poorer between-assay precision in respect to that observed for thyroxine.

The LIA-mat results were compared with those obtained by RIA Spac $T_{3}$ and $T_{4}$ methods by assaying about 100 samples from normals and patients; the regression analysis, reported in table 2 , indicates a good agreement between the two techniques.

Tab. 2. Regression analysis of LIA-mat (y) against RIA Spac (x) results

Triiodothyronine,

concentration range $0.8-4.2 \mathrm{nmol} / \mathrm{l}\left(\mathrm{n}=95^{*}\right)$

$\mathrm{y}=-0.08+1.04 \times \mathrm{nmol} / \mathrm{l} ; \mathrm{r}=0.82$

Thyroxine,

concentration range $6.4-270 \mathrm{nmol} / 1\left(\mathrm{n}=111^{*}\right)$

$\mathrm{y}=8.9+0.92 \times \mathrm{nmol} / \mathrm{l} ; \mathrm{r}=0.95$

* samples from eu-, hypo- and hyperthyroid patients

The system LIA-mat was also compared with another luminescent technique (the system Amerlite set up by Amersham International) by assaying samples from normals and patients. The results of the two techniques, reported in figure 4, were in good agreement.

In conclusion, the LIA-mat technique for the determination of triiodothyronine and thyroxine shows analytical reliability similar to that of RIA methods.
It is fast and easy to be performed and therefore represents a suitable alternative to the traditional isotopic immunoassay when the use of radioactivity is to be avoided.
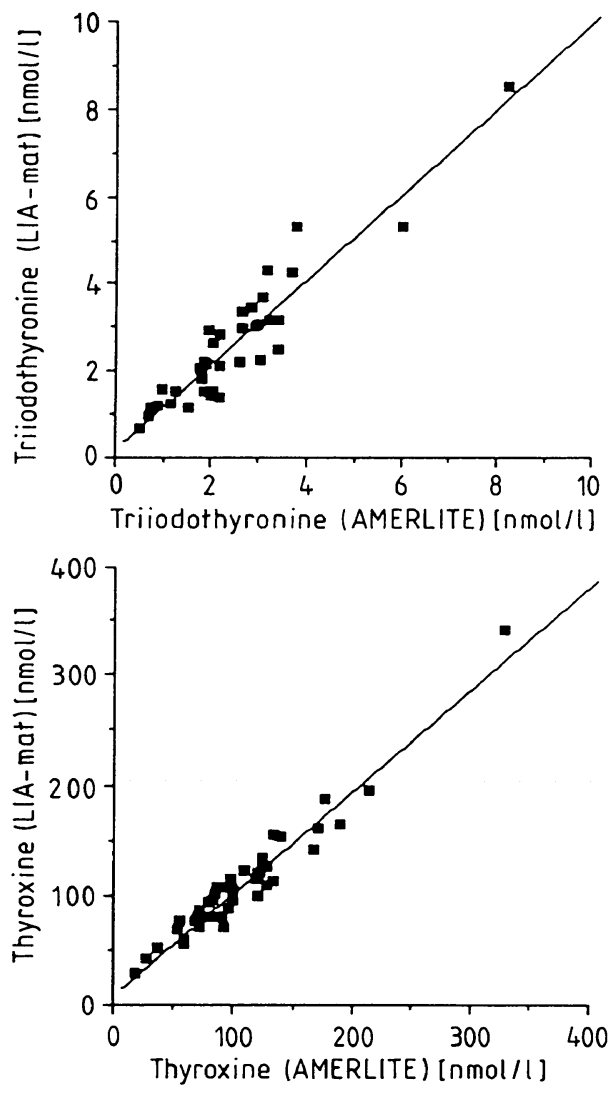

Fig. 4. Regression analysis of LIA-mat T3 results (upper panel: $\mathrm{y}=0.20+0.98 \mathrm{x}, \mathrm{r}=0.93, \mathrm{n}=37)$ and LIA-mat $\mathrm{T} 4$ results (lower panel: $\mathrm{y}=8.51+0.93 \mathrm{x}, \mathrm{r}=0.97$, $\mathrm{n}=45$ ) against the determinations produced by a chemiluminescence enhanced enzyme immunoassay (Amerlite) in samples from normals and patients. 


\section{References}

1. Whitehead, T. P., Kricka, L. J., Carter, T. J. N. \& Thorpe, G. H. G. (1979) Analytical luminescence: its potential in the clinical laboratory. Clin. Chem. 25, 1531-1546.

2. Schroeder, H. R., Yeager, F. M., Boguslaski, R. C. \& Vogelhut, P. O. (1979) Immunoassay for serum thyroxine mon- : itored by chemiluminescence. J. Immun. Meth. 25, 275282.

3. Kohen, F., Pazzagli, M., Serio M., de Boever, J. \& Vandekerckhove, D. (1985) Chemiluminescence and bioluminescence immunoassays. In: Alternative Immunoassays (Collins, W. P., ed.) pp. 103-122, John Wiley \& Sons, London, New York, Sydney, Toronto.

4. Zucchelli, G. C., Pilo, A., Chiesa, M. R. \& Piro, M. A. (1984) Progress report on a national quality control survey of T3 and T4 assay. Clin. Chem. 30, 393-395.
5. Whitehead, T. P., Thorpe, G. H. G., Carter, T. J. N., Groucutt, C. \& Kricka, L. J. (1983) Enhanced luminescence procedure for sensitive determination of peroxidase-labelled conjugates in immunoassay. Nature $305,158-159$.

6. Ekins, R. P. (1983) The precision profile: its use in assay design, assessment and quality control. In: Immunoassay for clinical chemistry (Hunter, W. M. \& Corrie, J. E. T., eds.) pp. 76-105, Churchill Livingstone Edinburgh.

7. Pilo, A., Zucchelli, G. C., Malvano, R. \& Masini, S. (1982) Main features of computer algorithms for RIA data reduction; comparison of some different approaches for the interpolation of the dose-response curve. J. Nucl. Med. All. Sci. 26, 235-248.

8. Pilo, A., Zucchelli, G. C., Chiesa, M. R. \& Ferdeghini, M. (1987) Performances of IRMAs vs RIAs compared through their precision profiles (abstract). Nuklearmedizin $26,144-$ 145.

Dr. G. C. Zucchelli

Istituto di Fisiologia Clinica C. N. R. via Savi 8

I-56100 Pisa 
